\title{
Functional variants of OCTN cation transporter genes are associated with Crohn disease
}

\author{
Vanya D Peltekova ${ }^{1,2}$, Richard F Wintle ${ }^{3}$, Laurence A Rubin ${ }^{1,3,4}$, Christopher I Amos ${ }^{5}$, Qiqing Huang ${ }^{5}$, \\ Xiangjun $\mathrm{Gu}^{5}$, Bill Newman ${ }^{1,2}$, Mark Van Oene ${ }^{3}$, David Cescon ${ }^{1,2}$, Gordon Greenberg ${ }^{1}$, Anne M Griffiths ${ }^{6}$, \\ Peter H St George-Hyslop ${ }^{1,3,7}$ \& Katherine A Siminovitch ${ }^{1-3}$
}

Crohn disease is a chronic, inflammatory disease of the gastrointestinal tract. A locus of $\sim 250 \mathrm{~kb}$ at $5 \mathrm{q} 31$ (IBD5) ${ }^{1,2}$ was previously associated with susceptibility to Crohn disease, as indicated by increased prevalence of a risk haplotype of 11 single-nucleotide polymorphisms ${ }^{3}$ among individuals with Crohn disease, but the pathogenic lesion in the region has not yet been identified. We report here that two variants in the organic cation transporter cluster at $5 q 31$ (a missense substitution in SLC22A4 and a G $\rightarrow$ C transversion in the SLC22A5 promoter) form a haplotype associated with susceptibility to Crohn disease. These variants alter transcription and transporter functions of the organic cation transporters and interact with variants in another gene associated with Crohn disease, CARD15, to increase risk of Crohn disease. These results suggest that SLC22A4, SLC22A5 and CARD15 act in a common pathogenic pathway to cause Crohn disease.

By resequencing the five genes in the IBD5 interval, we identified ten new single-nucleotide polymorphisms (SNPs; Supplementary Table 1 online), including two in the organic cation transporter (OCTN) gene cluster (SLC22A4 and SLC22A5, encoding OCTN1 and OCTN2, respectively) that are predicted to have functional effects. The first is a $\mathrm{C} \rightarrow \mathrm{T}$ substitution in SLC22A4 exon $9(1672 \mathrm{C} \rightarrow \mathrm{T}$; numbered according to the cDNA sequence for SLC22A4 in GenBank) that causes the amino acid substitution L503F. Leucine or isoleucine is conserved at this position in most OCTNs and other related transporters ${ }^{4}$ (Fig. 1a), and its substitution with phenylalanine is predicted computationally (by PolyPhen ${ }^{5}$, TMHMM2 (ref. 6) and PHAT transmembrane database $^{7}$ ) to be nonconservative. The second SNP is a $\mathrm{G} \rightarrow \mathrm{C}$ transversion in the SLC22A5 promoter $(-207 \mathrm{G} \rightarrow \mathrm{C})$, which disrupts a heat shock element (HSE) 207 bp upstream of the start codon (Fig. 1b).
$1672 \mathrm{C} \rightarrow \mathrm{T}$ and $-207 \mathrm{G} \rightarrow \mathrm{C}$ are in strong linkage disequilibrium and create a two-allele risk haplotype (TC) enriched in individuals with Crohn disease (frequency $=0.54$ in affected individuals versus 0.42 in controls, $P=0.0003$; Table 1). Odds ratios conferred by allele $1672 \mathrm{~T}$, allele $-207 \mathrm{C}$ or the TC haplotype were similar. Population

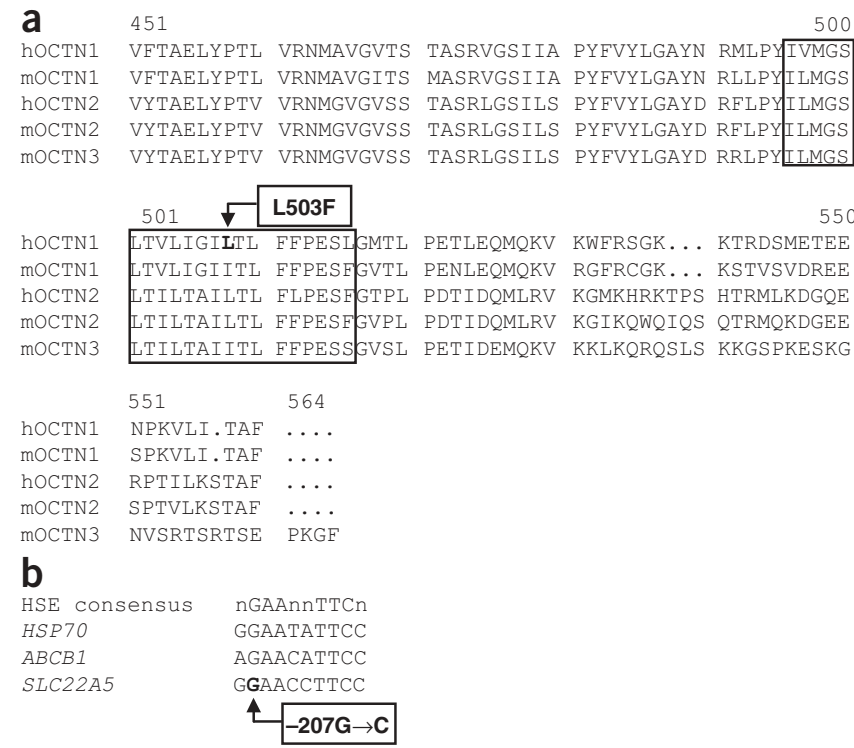

Figure 1 Sequence variants associated with Crohn disease. (a) Alignment of the C-terminal regions of OCTN proteins in humans $(\mathrm{h})$ and mice $(\mathrm{m})$. The L503F variant in the OCTN1 11 th transmembrane domain (box) is indicated. (b) Heat shock elements (HSEs) from HSP7O, ABCB1 and $S L C 22 A 5$ and a consensus HSE. The $-207 G \rightarrow C$ variant is indicated.

${ }^{1}$ Department of Medicine, University of Toronto, University of Toronto, Toronto, Ontario, Canada, M5S 1A1. ${ }^{2}$ Departments of Immunology and of Medical Genetics and Microbiology, University of Toronto, Mount Sinai Hospital Samuel Lunenfeld Research Institute, and Toronto General Research Institutes, Toronto, Ontario, Canada. ${ }^{3}$ Ellipsis Biotherapeutics Corporation, 700 Bay Street, Suite 2101, Toronto, Ontario M5G 1Z6, Canada. ${ }^{4}$ Division of Rheumatology, St. Michael's Hospital, 30 Bond St., Toronto, Ontario M5B 1W8, Canada. ${ }^{5}$ Department of Epidemiology, University of Texas, MD Anderson Cancer Center, 1515 Holcombe Boulevard, Houston, Texas 77030, USA. ${ }^{6}$ Department of Pediatrics, University of Toronto and The Hospital for Sick Children, Toronto, Ontario, Canada. ${ }^{7}$ Centre for Research in Neurodegenerative Diseases, Tanz Neuroscience Building, University of Toronto, 6 Queen's Park Crescent West, Toronto, Ontario M5S 3H2, Canada, and the University Health Network, Toronto, Ontario, Canada. Correspondence should be addressed to K.A.S. ( ksimin@ellipsisbiotherapeutics.com). 
a
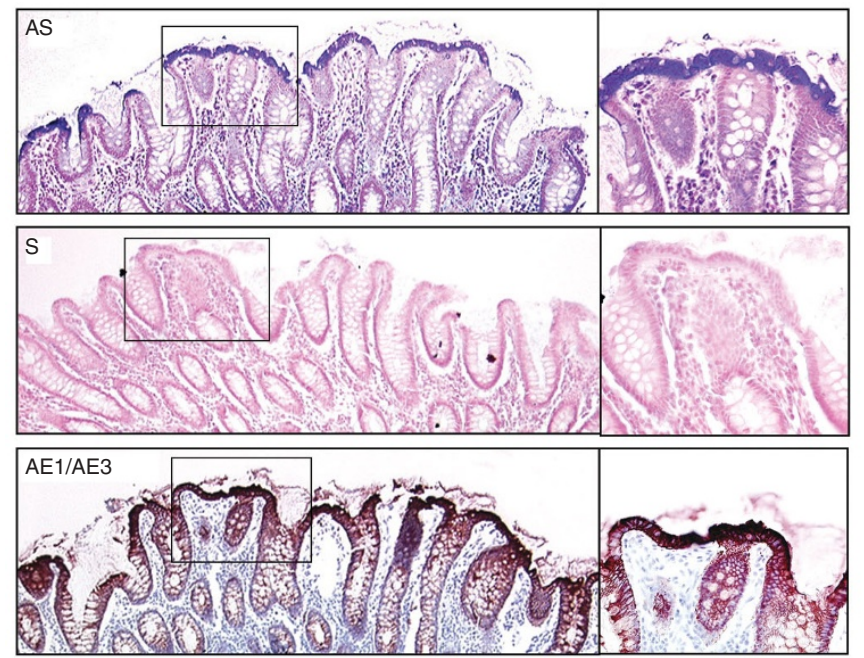

b
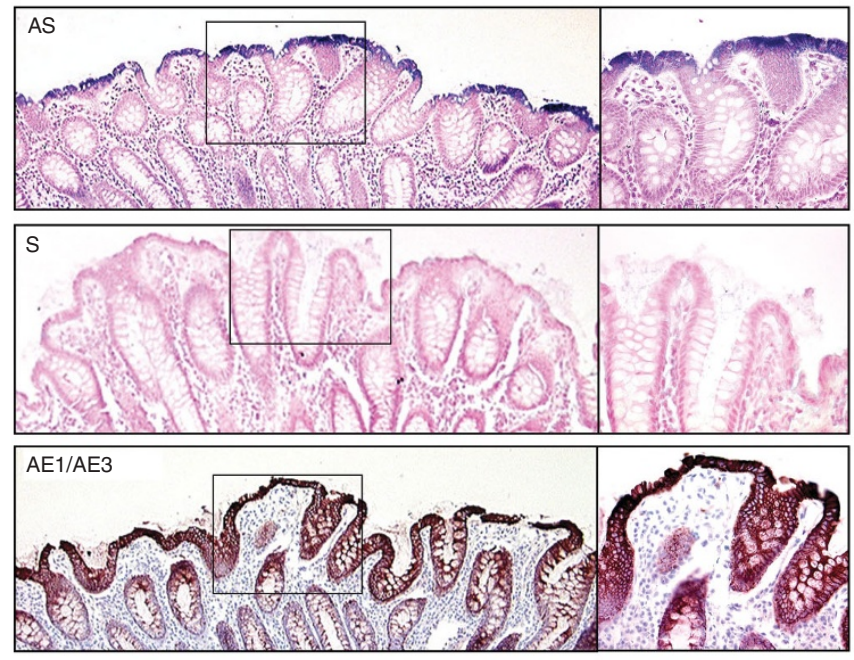

Figure 2 Distribution of SLC22A4 and SLC22A5 transcripts in human colon. Photomicrographs ( $\times 10$; right boxes $\times 40$ ) of human colon tissue hybridized with SLC22A4 (a) or SLC22A5 (b) antisense probes (AS, blue stain; top panels) or sense probes (S; center panels) or subjected to immunohistochemical analysis with antibody to cytokeratin (AE1/AE3, brown stain; bottom panels).

risk attributable to the TC haplotype was $19 \%$ for heterozygotes and $27 \%$ for homozygotes. A dose-effect test rejected recessive inheritance $\left(\chi^{2}=4.3, P=0.04\right)$ but supported both dominant $\left(\chi^{2}=1.19\right.$, $P=0.28)$ and additive $\left(\chi^{2}=0.35, P=0.56\right)$ inheritance. Risk for disease in both a discovery and an independently collected replication cohort was similarly increased by presence of either the TC haplotype or at least one of the three main alleles of CARD15 associated with Crohn disease ${ }^{8}$. Consistent with interaction between the IBD5 locus and CARD15 variants associated with Crohn disease ${ }^{9}$, risk for disease was much greater in the presence of both the TC haplotype and the Crohn disease-associated CARD15 alleles (Table 1). IBD5 may also be associated with ulcerative colitis ${ }^{10}$, but the TC haplotype did not influence disease risk in 216 individuals with ulcerative colitis that we studied $(P=0.17)$.

Among individuals lacking IBD5 risk haplotypes (i.e., homozygous with respect to the non-risk-associated allele of IGR2078a_1, a surrogate marker for the extended IBD5 haplotype $\left.{ }^{3,9}\right), 53 \%$ of individuals with Crohn disease $(n=99)$ but only $23 \%$ of controls $(n=120)$ carried at least one $1672 \mathrm{~T}$ or $-207 \mathrm{C}$ allele $\left(P=2 \times 10^{-6}\right)$. Haplotypes with at least one $1672 \mathrm{~T}$ or $-207 \mathrm{C}$ allele on the non-risk-associated IBD5 background were also more frequent in individuals with Crohn disease $(0.143, n=370)$ than in controls $\left(0.098, n=246 ; P=3.5 \times 10^{-9}\right)$. By contrast, the haplotype containing the IBD5 risk allele but neither of the $1672 \mathrm{~T}$ or $-207 \mathrm{C}$ alleles was almost as frequent among affected individuals as controls $(0.012$ versus 0.013$)$. These data argue that the SLC22A4 and SLC22A5 $1672 \mathrm{~T}$ and $-207 \mathrm{C}$ variants per se, rather than other nearby alleles, confer risk for Crohn disease. Although the SLC22A4-SLC22A5 interval has been hypothesized to contain an IBDrelated human ortholog to the mouse gene Slc22a9 (ref. 11), we and others were unable to identify a human Slc22a9 counterpart or any other gene in this region.

SLC22A4 and SLC22A5 are widely expressed ${ }^{11-14}$, but in situ hybridization data showed that they were specifically expressed in the principal intestinal cell types affected by Crohn disease, including epithelial cells (Fig. 2), $\mathrm{CD} 68^{+}$macrophages and $\mathrm{CD} 43^{+} \mathrm{T}$ cells, but not CD20+ B cells (Supplementary Fig. 1 online). This expression pattern is consistent with the multisystem nature of Crohn disease and involvement of these genes in susceptibility to Crohn disease.

SLC22A4 and SLC22A5 encode the polytopic transmembrane sodium-dependent carnitine and sodium-independent organic cation transporters OCTN1 and OCTN2 (ref. 4). The L503F substitution in OCTN1 maps to a region (the 11th transmembrane domain) required for transport function ${ }^{15,16}$ and may therefore alter this activity. We investigated OCTN1 function in fibroblasts and found carnitine uptake to be 2.7 times lower in cells expressing 503F than in those expressing 503L (Fig. 3a). Although both the

Table 1 Linkage disequilibrium and Crohn disease association data

\begin{tabular}{|c|c|c|c|c|c|c|c|}
\hline \multirow[b]{2}{*}{ Data set } & \multirow[b]{2}{*}{$n$} & \multirow[b]{2}{*}{$D^{\prime}$} & \multirow[b]{2}{*}{$r^{2}$} & \multicolumn{4}{|c|}{ Odds ratios } \\
\hline & & & & Homozygous TC & Heterozygous TC & CARD15 & Joint TC-CARD15 \\
\hline Discovery cases & 203 & 0.95 & 0.62 & $\begin{array}{c}3.43(1.58-7.44), \\
P=0.002\end{array}$ & $\begin{array}{c}2.10(1.03-4.28), \\
P=0.041\end{array}$ & $\begin{array}{c}2.10(1.31-3.39), \\
P=0.0011\end{array}$ & $\begin{array}{c}7.28(2.63-24.79) \\
P<0.0001\end{array}$ \\
\hline Discovery controls & 200 & 0.86 & 0.57 & - & - & - & - \\
\hline Replication cases & 300 & 0.79 & 0.45 & $\begin{array}{c}5.14(2.52-10.45) \\
P<0.001\end{array}$ & $\begin{array}{c}2.56(1.42-4.60), \\
P=0.002\end{array}$ & $\begin{array}{c}2.50(1.54-4.04), \\
P<0.001\end{array}$ & $\begin{array}{c}10.50(3.31-36.27) \\
P<0.0001\end{array}$ \\
\hline Replication controls & 190 & 0.99 & 0.70 & - & - & - & - \\
\hline
\end{tabular}

$D^{\prime}$ and $r^{2}$ between SLC22A4 1672C $\rightarrow$ T and SLC22A5 -207G $\rightarrow$ C are indicated. Odds ratios for susceptibility to Crohn disease, 95\% confidence intervals (in parentheses) and significance are shown for the TC haplotype, presence of a CARD15 mutation and for the joint TC-CARD15 effect. 


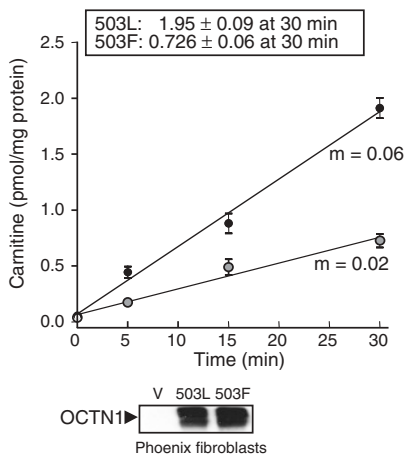

e

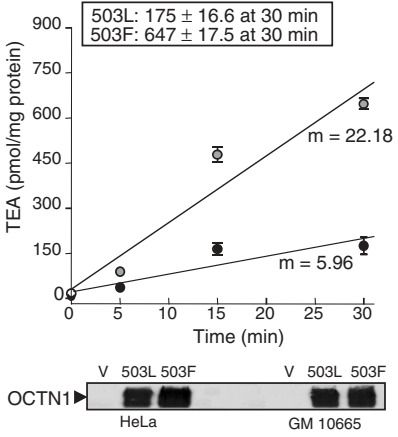

b

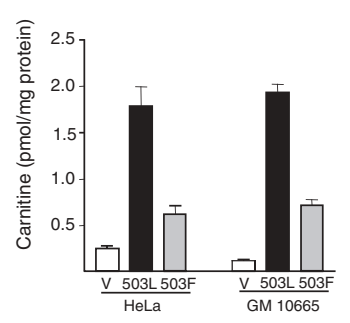

f

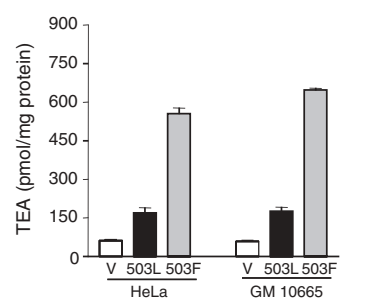

C

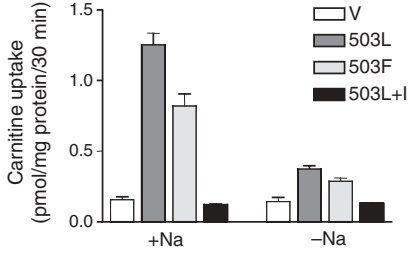

g

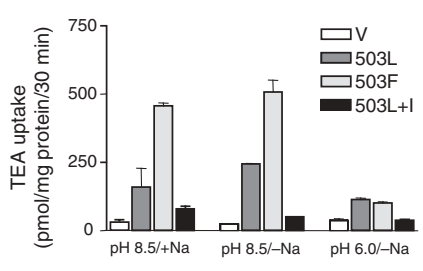

d

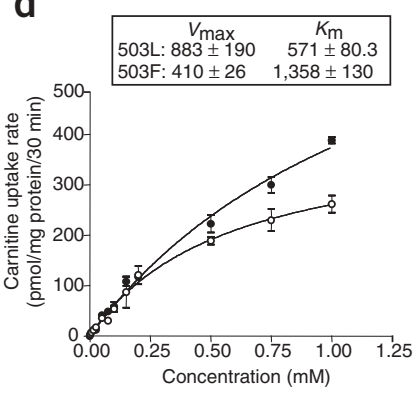

h

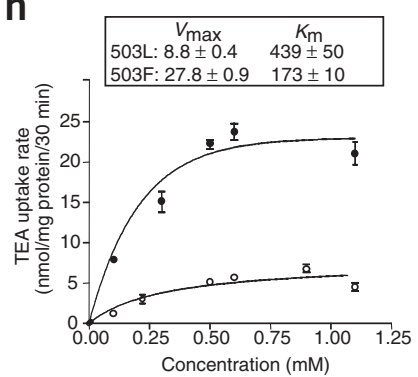

Figure 3 Transport of carnitine and TEA by OCTN1. Transport by cells expressing the 503L variant (black circles or boxes), the 503F variant (shaded circles or boxes) or empty vector $(\mathrm{V})$ over a time course $(\mathbf{a}, \mathbf{e})$ or $30 \mathrm{~min}$ after loading $(\mathbf{b}, \mathbf{f})$. Linear regression slopes $(\mathrm{m})$ are indicated. Immunoblots $(\mathbf{a}, \mathbf{e}$ bottom panels) show OCTN1 protein in transfected cells. Effects of sodium on carnitine uptake (c) and of sodium and pH on TEA uptake (g) are indicated. I, nonspecific inhibitor ( $5 \mathrm{mM}$ quinidine). Concentration dependence, $V_{\max }$ (carnitine, pmol per $\mathrm{mg}$ of protein per min; TEA, nmol per mg of protein per min) and $K_{\mathrm{m}}(\mu \mathrm{M})$ of uptake of $\left[{ }^{3} \mathrm{H}\right]$-carnitine and $\left[{ }^{14} \mathrm{C}\right]-\mathrm{TEA}$ are shown $(\mathbf{d}, \mathbf{h})$.

503F and 503L variants transport carnitine in sodium- and concentration-dependent fashions (Fig. 3c,d), the $503 \mathrm{~F}$ variant had a lower $V_{\max }$ and higher $K_{\mathrm{m}}$ for carnitine uptake (Fig. 3d). Although the $503 \mathrm{~F}$ and $503 \mathrm{~L}$ variants also transported tetraethyl ammonium (TEA) in a sodium-independent but $\mathrm{pH}$-dependent manner (Fig. $3 \mathrm{~g}$ ), the $503 \mathrm{~F}$ variant was associated with 3.7 times greater TEA uptake (Fig. 3e) and a higher $V_{\max }$ and lower $K_{\mathrm{m}}$ for TEA uptake

Table 2 Effects of endogenous compounds and xenobiotics on TEA uptake in cells expressing OCTN1 503L and OCTN1 503F

\begin{tabular}{lcc}
\hline & \multicolumn{2}{c}{$K_{\mathrm{i}}(\mu \mathrm{M})$} \\
\cline { 3 - 3 } Compounds & $503 \mathrm{~L}$ & $503 \mathrm{~F}$ \\
\hline Endogenous substrates & $24.08 \pm 3.01^{*}$ & $3,642.0 \pm 221.8$ \\
L-carnitine & $230.50 \pm 47.05^{*}$ & $864.9 \pm 110.5$ \\
Choline & $76.66 \pm 24.96^{*}$ & $621.0 \pm 59.95$ \\
N-methylnicotinamide & & \\
Competitive xenobiotics & $439.01 \pm 32.31^{*}$ & $172.93 \pm 21.83$ \\
TEA & $535.00 \pm 54.85^{*}$ & $141.70 \pm 25.53$ \\
Tetrabutyl ammonium & $69.56 \pm 0.05^{*}$ & $10.67 \pm 0.40$ \\
Tetrapentyl ammonium & & \\
Noncompetitive xenobiotics & $8.38 \pm 0.20^{*}$ & $22.31 \pm 2.98$ \\
Verapamil & $434.80 \pm 19.07^{*}$ & $1,658.00 \pm 142.0$ \\
Cimetidine & $0.83 \pm 0.02^{*}$ & $21.06 \pm 1.83$ \\
Lidocaine & $68.38 \pm 8.89$ & $60.99 \pm 8.45$ \\
Quinidine & & \\
\hline
\end{tabular}

${ }^{*} P<0.05$, Student's $t$-test.
(Fig. 3h). We observed similar effects in HeLa cells and OCTN2deficient fibroblasts (Fig. 3b,f).

OCTN1 was previously characterized as a low-affinity carnitine transporter ${ }^{17}$, but this conclusion was based on analysis of the $503 \mathrm{~F}$ variant rather than the more prevalent wild-type 503L variant, shown here to be a better carnitine transporter. The $503 \mathrm{~F}$ variant also had less affinity for carnitine and other endogenous substrates but greater affinity for TEA and various xenobiotics (Table 2) than the wild-type 503L variant. Collectively, these results confirm that the L503F substitution substantially alters OCTN1 function.

The $-207 \mathrm{G} \rightarrow \mathrm{C}$ substitution in SLC22A5 occurs within a heatshock transcription factor (HSF)-binding element (HSE) ${ }^{18,19}$. We therefore used gel shift assays to evaluate inducible HSF binding to the SLC22A5 HSE. We found that a radioactively labeled oligonucleotide corresponding to the $-207 \mathrm{G}$ (wild-type) HSE formed high-molecular-weight complexes with nuclear extracts from heatshocked or arachidonic acid-stimulated cells. We also found that mobilities of these complexes were supershifted by antibody to HSF1 but not by antibody to HSF2 (Fig. 4). In contrast, an oligonucleotide corresponding to the $-207 \mathrm{C}$ (Crohn disease-associated) HSE formed no complexes. Like nonspecific oligonucleotides, unlabeled competitor $-207 \mathrm{C}$ oligonucleotide had no effect on $-207 \mathrm{G}$ binding activity (Fig. 4a).

We also examined effects of the $-207 \mathrm{C}$ variant on HSF-induced SLC22A5 transcriptional activation using a luciferase reporter driven by a SLC22A 5 promoter segment containing either $-207 \mathrm{C}$ or $-207 \mathrm{G}$. Increases in promoter activity evoked by HSF were significantly greater in OCTN2-deficient fibroblasts expressing -207G than in 
a

b

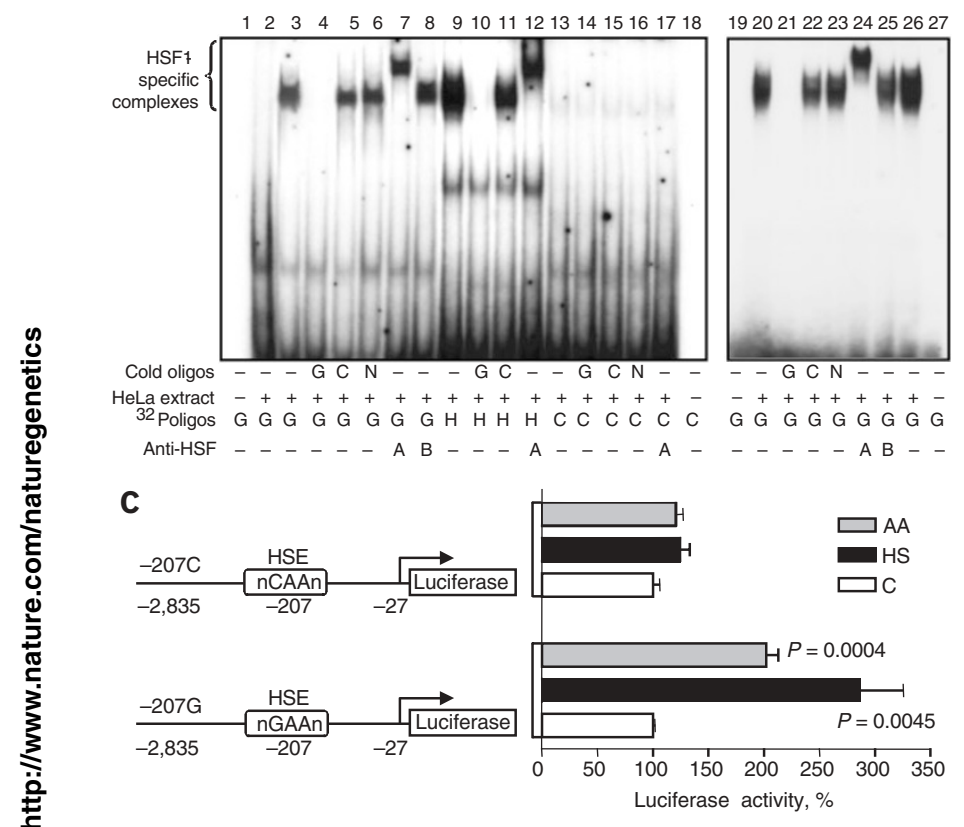

Figure 4 Effects of SLC22A5-207G $\rightarrow$ C on heat shock-inducible HSE binding and promoter activity. (a) Gel-shift assay with radioactively labeled $-207 G(G),-207 C$ (C) or HSP7O (H) HSE and nuclear extracts from heatshocked (lanes 1, 3-17) or untreated (lane 2) HeLa cells. Unlabeled (cold) $-207 G(G),-207 C(C)$ or nonspecific (N) competitor oligonucleotides and antibodies to HSF-1 (A) or HSF-2 (B) are indicated. (b) Gel-shift assay in untreated cells (lane 26) or cells treated with arachidonic acid (lanes 19-25,27). (c) SLC22A5 promoter assays. Luciferase activity from $-207 G$ or $-207 \mathrm{C}$ variants left untreated (C), heat-shocked (HS) or treated with arachidonic acid (AA) and statistically significant differences from untreated cells are shown.

those expressing -207C (heat-shocked cells, 2.3 times higher; arachidonic acid-stimulated cells, 1.7 times higher; Fig. 4c). Increases in promoter activity evoked by HSF were also significantly greater in HeLa cells expressing $-207 \mathrm{G}$ than in those expressing -207C (2.2 times higher, $P=0.0001$; data not shown). These results suggest that the $-207 \mathrm{C}$ variant disrupts a functional promoter element.

The data reported here identify variants of SLC22A4 and $S L C 22 A 5$ that increase susceptibility to Crohn disease. Our data and a previous study of rheumatoid arthritis ${ }^{20}$ suggest that these genes have a role in chronic inflammatory disorders. These variants may cause disease by impairing OCTN activity or expression, reducing carnitine transport in a cell-type and disease-specific manner. Defects in oxygen burst-mediated pathogen killing or impaired fatty acid $\beta$-oxidation in intestinal epithelium may ensue, the latter of which is exacerbated by bacterial metabolites and causes colitis in experimental model ${ }^{21,22}$. Alternatively, the effects of the 503F variant on OCTN1 transporter specificity may also diminish uptake of physiologic compounds while increasing uptake of potential toxins, such as putrescine, derived from bacterial catabolism. In either scenario, a role for OCTNs in handling enteric bacteria or their byproducts is consistent with the putative effects of CARD15 mutations on cellular responses to bacterial products and provides a basis for the genetic interaction between these loci.

The L503F substitution probably has modest effects on OCTN1 function, perhaps substantial only under metabolic stress conditions. The SLC22A5 promoter variant and the intronic variant in SLC22A4 associated with rheumatoid arthritis ${ }^{20}$ probably become important only after relevant transcription factor activation. Also, as observed for genes associated with other complex diseases ${ }^{23,24}$, the OCTN variants are prevalent in the general population. These observations do not, however, mitigate their potential pathogenicity. The strong interaction between SLC22A4, SLC22A5 and CARD15 in Crohn disease and the suggested interaction between SLC22A4 and RUNX1 in rheumatoid arthritis suggest that OCTNs participate in multiple pathways underlying chronic inflammation. Our discovery provides a basis for diagnostic tests for Crohn disease risk and identifies the OCTNs as potential targets for therapeutic interventions.

\section{METHODS}

We recruited unrelated individuals of European origin as described ${ }^{1}$. Replication cases were an independent cohort from the same center. We randomly selected healthy controls of European descent (average age 26 years) from 1,000 anonymous samples. We obtained ethics approval from the University of Toronto and informed consent from all subjects. Genotyping was done by single base extension (Beckman Coulter SNPstream) or allelespecific $\mathrm{PCR}^{25}$. Primer sequences are available on request. We determined haplotype frequencies through maximum likelihood estimation and the dose effect by a likelihood ratio test.

We transfected SLC22A4 (1672C or 1672T) cDNAs into HeLa, GM 10665 or HEK293 fibroblasts using lipofectamine and evaluated them for carnitine or TEA uptake (in triplicate) in transport buffer ( $\mathrm{pH} 8.5$ or 6.0) in which $\mathrm{NaCl}$ was replaced isotonically with $\mathrm{N}$-methyl-D-glucamine. We determined kinetics and $K_{\mathrm{i}}$ values for SLC22A4 transport and inhibition in stably transfected HEK293 by subtracting background uptake ( $5 \mathrm{mM}$ quinidine).

We used digoxigenin-UTP-labeled sense or antisense riboprobes for wholemount in situ hybridizations as described ${ }^{26}$. We used antibodies to digoxigenin conjugated with alkaline phosphatase to detect hybridized probes. We counterstained sections with Fast Nuclear Red (Dako). We used monoclonal antibodies (Dako) against cytokeratin AE1/AE3 (1:100), CD20 (1:500), CD42 (1:400) and CD68 (1:100) for immunostaining.

For gel shift assays, we took nuclear extracts $(10 \mu \mathrm{g})$ from HeLa cells, left some untreated, heat-shocked some at $42^{\circ} \mathrm{C}$ for $2 \mathrm{~h}$ and incubated some with $20 \mu \mathrm{M}$ arachidonic acid for $30 \mathrm{~min}$. We incubated nuclear extracts with ${ }^{32}$ P-labeled or unlabeled $(100 \times)$ oligonucleotides (SLC22A5 nucleotides -199 to -223 or $H S P 70 \mathrm{HSEs}^{27}$ ). For supershifts, we used antibodies to HSF1 or HSF2 (SantaCruz).

We transfected the SLC22A5 promoter regions ( $-2.7 \mathrm{~kb}$ from ATG) carrying $-207 \mathrm{C}$ or $-207 \mathrm{G}$ alleles in the pRL-null reporter vector (Promega) into HeLa or GM10665 cells. After $24 \mathrm{~h}$, we subjected cells heat shock at $42^{\circ} \mathrm{C}$ for $2 \mathrm{~h}$ or incubated them with $20 \mu \mathrm{M}$ arachidonic acid for $30 \mathrm{~min}$ and assayed them for luciferase activity after $18 \mathrm{~h}$.

\section{GenBank accession number. SLC22A4 cDNA, NM_003059.}

Note: Supplementary information is available on the Nature Genetics website.

\section{ACKNOWLEDGMENTS}

We thank J. Owen, M. Mackowiecki, X. Tian, S. Alic, K. Wong, M. Chase, M. Yazdanpanah, R. McLeod and J. Wood for their contributions and S. Sunyaev for discussions. This work was supported by Ellipsis Biotherapeutics Corporation, Canadian Institutes of Health Research, Crohn's and Colitis Foundation of Canada, Canadian Genetic Diseases Network, Genome Canada, Howard Hughes Medical Foundation, National Institutes of Health and the Industrial Research Assistance Program (Canadian National Research Council). K.A.S. is a Canadian Institutes of Health Research Senior Scientist and a University of Toronto McLaughlin Centre for Molecular Medicine Scientist. P.H.S.-H. is a Howard Hughes Medical Foundation Scholar and a Canadian Institutes of Health Research Senior Scientist. B.N. was supported by fellowships from the Canadian Arthritis Network and Arthritis Society of Canada.

\section{COMPETING INTERESTS STATEMENT}

The authors declare competing financial interests (see the Nature Genetics website for details). 
Received 23 January; accepted 25 February 2004

Published online at http://www.nature.com/naturegenetics/

1. Rioux, J.D. et al. Genome wide search in Canadian families with inflammatory bowe disease reveals two novel susceptibility loci. Am. J. Hum. Genet. 66, 1863-1870 (2000).

2. Ma, Y. et al. A genome-wide search identifies potential new susceptibility loci for Crohn's disease. Inflamm. Bowel Dis. 5, 271-278 (1999).

3. Rioux, J.D. et al. Genetic variation in the $5 q 31$ cytokine gene cluster confers susceptibility to Crohn disease. Nat. Genet. 29, 223-228 (2001).

4. Burckhardt, G. \& Wolff, N.A. Structure of renal organic anion and cation transporters Am. J. Physiol. Renal Physiol. 278, F853-F866 (2000).

5. Ramensky, V., Bork, P. \& Sunyaev, S. Human non-synonymous SNPs: server and survey. Nucleic Acids Res. 30, 3894-3900 (2002).

6. Krogh, A., Larsson, B., von Heijne, G. \& Sonnhammer, E.L.L. Predicting transmembrane protein topology with a hidden Markov model: Application to complete genomes. J. Mol. Biol. 305, 567-580 (2001).

7. Ng, P.C., Henikoff, J.G \& Henikoff, S. PHAT: a transmembrane-specific substitution matrix. Predicted hydrophobic and transmembrane. Bioinformatics. 16, 760-766 (2000).

8. Newman, B. et al. CARD15 and HLA DRB1 alleles influence susceptibility and disease localization in Crohn's disease. Am. J. Gastroenterol. 99, 306-314 (2004).

9. Mirza, M.M. et al. Genetic evidence for interaction of the $5 q 31$ cytokine locus and the CARD15 gene in Crohn Disease. Am. J. Hum. Genet. 72, 1018-1022 (2003).

10. Giallourakis, C. et al. IBD5 is a general risk factor for inflammatory bowel disease: replication of association with Crohn disease and identification of a novel association with ulcerative colitis. Am. J. Hum. Genet. 73, 205-211 (2003).

11. Lamhonwah, A.M., Skaug, J., Scherer, S.W. \& Tein, I. A third human carnitine/organic cation transporter (OCTN3) as a candidate for the 5q31 Crohn's disease locus (IBD5). Biochem. Biophys. Res. Commun. 301, 98-101 (2003).

12. Wu, X., et al. Structural and functional characteristics and tissue distribution patterns of rat OCTN1, an organic cation transporter, cloned from placenta. Biochem. Biophys. Acta 1466, 315-327 (2000).

13. Wu, X. et al. Functional characteristics and tissue distribution pattern of organic cation transporter 2 (OCTN2), an organic cation/carnitine transporter. J. Pharmacol.
Exp. Ther. 290, 1482-1492 (1999).

14. Elimrani, I. et al. Expression and localization of organic cation/carnitine transporter OCTN2 in Caco-2 cells. Am. J. Physiol. Gastrointest. Liver Physiol. 284, G863-G871 (2003).

15. Seth, P., Wu, X., Huang,W., Liebach, F.H. \& Ganapathy, V. Mutation in novel organic cation transporter (OCTN2), an organic cation/carnitine transporter, with differential effects on the organic cation transport function and the carnitine transport function. J. Biol. Chem. 274, 33388-33392 (1999).

16. Durán, J.M., Peral, M.J., Calonge, M.L \& Ilundáin, A.A. Functional characterization of intestinal L-carnitine transport. J. Membr. Biol. 185, 65-74 (2002).

17. Tamai, I. et al. Cloning and characterization of a novel human $\mathrm{pH}$-dependent organic cation transporter OCTN1. FEBS Lett. 419, 107-111 (1997).

18. Wu, C. Heat shock transcription factors: structure and regulation. Annu. Rev. Cell Dev. Biol. 11, 441-469 (1995).

19. Jurivich, D.A., Sistonen, L., Sarge, K.D., \& Morimoto, R.I. Arachidonate is a potent modulator of human heat shock gene transcription. Proc. Natl. Acad. Sci. USA. 91, 2280-2284 (1994).

20. Tokuhiro, S. et al. An intronic SNP in a RUNX1 binding site of SLC22A4, encoding an organic cation transporter, is associated with rheumatoid arthritis. Nat. Genet. 35, 341-348 (2003).

21. Ramsay, R.R. The carnitine acyltransferases: modulators of acyl-CoA-dependent reactions. Biochem. Soc. Trans. 28, 182-186 (2000).

22. Roediger, W.E \& Nance, S. Metabolic induction of experimental ulcerative colitis by inhibition of fatty acid oxidation. Br. J. Exp. Pathol. 67, 773-782 (1986).

23. Wilson, P.W.F., Schaefer, E.J., Larson, M.G. \& Ordovas, J.M. Apolipoprotein E alleles and risk of coronary artery disease. A meta-analysis. Arterioscler. Thromb. Vasc. Biol. 16, 1250-1255 (1996)

24. Saunders, A.M. et al. Association of apolipoprotein $E$ allele epsilon 4 with late-onset familial and sporadic Alzheimer's disease. Neurology 43, 1467-1472 (1993).

25. Newman, B., Rubin, L.A. \& Siminovitch, K.A. NOD2/CARD15 gene mutation is not associated with susceptibility to Wegener's Granulomatosis. J. Rheum. 30, 305-307 (2003).

26. Conlon, R.A \& Rossant, J. Exogenous retinoic acid rapidly induces anterior ectopic expression of murine Hox-2 genes in vivo. Development 116, 357-368 (1992).

27. Baler, R., Dahl, G. \& Voellmy, R. Activation of human heat shock genes is accompanied by oligomerization, modification and rapid translocation of heat shock transcription factor HSF1. Mol. Cell. Biol. 13, 2486-2496 (1993). 